\title{
Assessing Improvement and Professional Career Skills in Senior Capstone Design through Course Data
}

\author{
https://doi.org/10.3991/ijep.v7i3.7390 \\ Robert M. Stwalley III \\ Purdue University, West Lafayette, Indiana, USA \\ rms 3 @ purdue.edu
}

\begin{abstract}
An objective internal departmental review of course data indicates that a one credit hour fall seminar course which allows many preparatory topics to be engaged by the senior capstone teams makes the spring laboratory portion of the course run more smoothly. Professional topics such as team building, oral and written communication skills, and organizational interaction have been suggested by industrial partners and are now integrated into the course sequence before the students perform their physical work, reducing issues during the lab component. Course adjustments are on-going, and in the spirit of continuous improvement, those adjustments are periodically evaluated for effectiveness. It has been statistically demonstrated that the addition of an internally reviewed feasibility pitch early in the fall semester has resulted in better external reviews for both the fall management and spring technical design presentations. Likewise, providing the chance for the teams to see a video tape of their final presentation, before it is reviewed by various outside parties, has resulted in significantly better final presentations. In general, the formation of all engineering and mixed teams has been found to produce better end projects than those created by all technology-based student teams. These elements and other demonstrated positive changes to the Purdue University Agricultural \& Biological Engineering capstone sequence can be described as cultivating professional attributes, and the experience is reviewed in this paper.
\end{abstract}

Keywords-capstone; communications; course assessment; professionalism; seminar; teambuilding

\section{Introduction}

The purpose of this paper is to relay current information regarding a successful and adaptive capstone program to the broader capstone community. The undergraduate education programs of the Purdue University Agricultural and Biological Engineering (ABE) program are highly regarded, currently making the department one of the top US News \& World Report schools within this specialty [1]. Graduates of the program, especially the Agricultural Systems Management (ASM) students, are well sought-after by the department's industrial partners, and as shown in Figure 1 with data from the Purdue Center for Career Opportunities [2], the greater majority of seniors seeking employment have secured positions within a few months of graduation. The faculty 


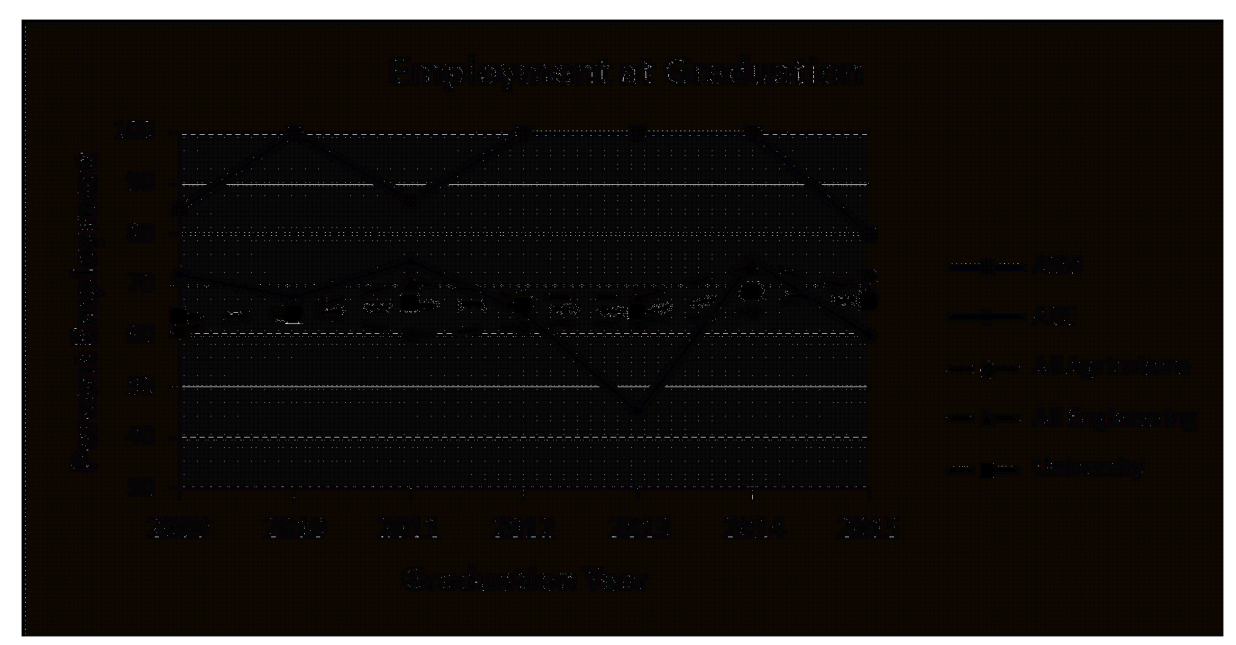

Fig. 1. Comparison of Professional Employment at Graduation.

and staff of the department believe that the senior capstone design sequence is one of the primary reasons for the successful integration of Purdue ABE students into entrylevel professional positions. The sequence is designed as a two semester consecutive series, with a project management seminar during the fall where students scope and generate solution ideas, followed by a spring laboratory phase where students actively complete their assignments. Project partner and instructor satisfaction with the courses is strong, and the faculty believe that the fall capstone seminar is one of the reasons that the sequence performs well and runs smoothly overall.

The capstone structure within ABE at Purdue is typical of many engineering departments as described by Howe and Wilbarger [3], and it presents much of the same content covered by other engineering capstone courses as reported by Howe et al. [4]. The greater majority of programs utilize a two semester sequence with classroom activities in the fall, followed by an intensive laboratory phase in the spring. However, the Purdue ABE sequence cannot be accurately described as either a parallel or sequential construct, rather it is a hybrid. Classroom activities do not continue into the spring semester, and students are expected to begin active scoping, idea generation, and concept evaluation during the fall, as these topics are covered during the class. This model does not fit the generally accepted parallel design. Neither can it accurately be described by the pre-course sequential model of project process topics or several preliminary mini-projects described by $\mathrm{Co}$ et al. [5], as several of these technical elements are actually covered in earlier required courses within the ABE plan of study. As suggested by Mohammed and Dimmitt [6], the Purdue ABE capstone sequence concentrates on improving the students' professional skills. Following the work of McVey and Lang [7], industrial expectations have been used to steer the curricular content. Informal focus groups conducted with departmental partners initially returned the same type of results described by Kimble-Thom and Thom [8], lacking specificity and definition. These results were unusable in steering curricular decisions, and follow-on sessions were used to develop more specific recommenda- 
tions on alternative designs, decision-making, sustainability, communication skills, and other needed industrial employment proficiencies. The faculty then refined those suggestions into specific course element evaluation rubrics, and the sequence curricular content was modified so that instruction could match the desired outcomes. Partner input and faculty adjustment are continuing features of the Purdue ABE capstone program. Changes in specific course evaluation rubric line items are checked against course modifications through time, and evaluation rubrics are periodically compared to those used by other Purdue academic departments and peer institutions. Although the evaluation instruments have not gone through the rigorous statistical validation process as described in the Iowa State competency-based outcomes work by Brumm et al. [9], ABET examines and comments upon these instruments as a portion of the department's larger accreditation review.

The main focus within Purdue ABE capstone is on the preparation for professional career success by training the students in project management skills, effective project execution, and the development of project deliverables that properly communicate the impact of the work. The capstone experience in ABE was introduced as an optional projects class in the mid-1970's, and it has evolved into a required two course sequence that initially concentrates on the design process and then transitions to an actual project laboratory with specific technical goals. All engineering students $(\sim 75 / \mathrm{yr})$ and ASM students $(\sim 50 / \mathrm{yr})$ are required to take this sequence to graduate. The department typically has around 30 teams per year averaging about three team members. Students are expected to invest about 5 hours per week outside of class during the fall and roughly 20 hours per week during the spring. Industrial project sponsors are not charged a participation fee, but they are expected to meet the required costs of the work. Internal projects within $\mathrm{ABE}$ are generally limited to $\$ 500$ total cost. The courses are generally well-regarded by the students in both the university mandated evaluations (unpublished Purdue ABE historical course surveys, compiled and reviewed by Purdue Center for Instructional Excellence, 2016) and the graduating senior exit interviews conducted by the department chairman (unpublished Purdue ABE Department Head / Graduate Exit Interviews, compiled and reviewed by Bernie Engel - Purdue ABE Head, 2016). Figure 2 shows that the student course satisfaction indicator, through the course modifications of the last five years, has been uniformly well received, and Table 1 displays some typical positive exit interviews.

The specific purpose of this paper is to relay the unique experiences of the Purdue $\mathrm{ABE}$ faculty in conducting and administering the department capstone course sequence, and it is intended for other faculty members in higher education that either do or will be teaching similar classes. This paper will relay the design of the Purdue ABE experience; discuss project solicitation, team selection, and academic topic coverage, including the presentation of successful professional life skills; examine the expected deliverables from the student teams; and cover the feedback provided by our students and external reviewers. 


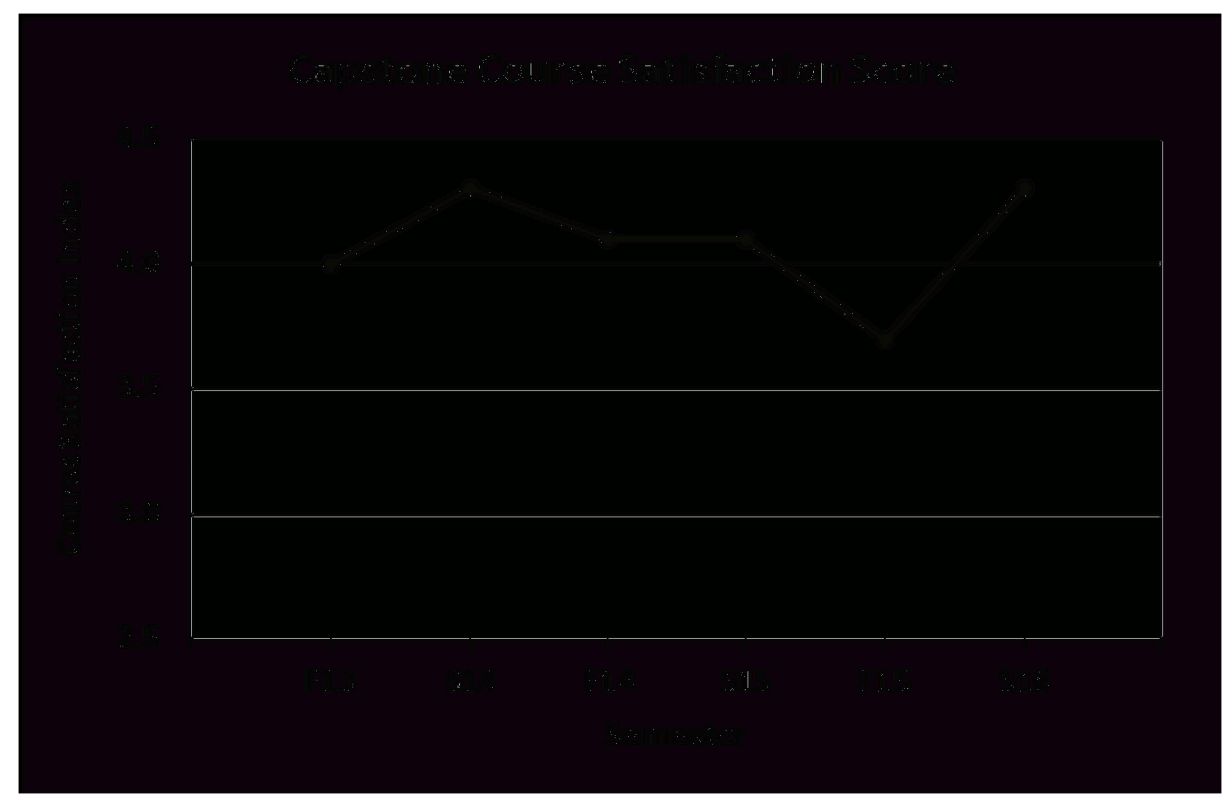

Fig. 2. Purdue ABE Capstone Course Student Satisfaction Index (0.0-5.0 scale).

Table 1. Selected Purdue ABE Capstone Student Comments.

\begin{tabular}{|l|}
\hline Capstone was a highlight. \\
\hline Dr. Engel cares for every student and wants them to succeed. \\
\hline Dr. Stwalley made the class interesting and contributed to my overall design skills \\
\hline Dr. Stwalley is very knowledgeable and keeps the class interesting with past work experiences. \\
\hline The assignments were fair and not too numerous. \\
\hline Dr. Engel is a great instructor, who was helpful and easy to reach. \\
\hline Dr. Stwalley is available for students to meet with him outside of class. \\
\hline Thank-you for clearing things with our sponsors. \\
\hline Great Job! \\
\hline $\begin{array}{l}\text { Dr. Stwalley \& Dr. Engel were very encouraging ... kept a positive tone ... great resource, that avoided } \\
\text { telling students exactly what to do. }\end{array}$ \\
\hline $\begin{array}{l}\text { (Your) Passion and wisdom when it comes to the work we are doing was very helpful and made me confi- } \\
\text { dent that we were gaining important skills. }\end{array}$ \\
\hline Lectures are always very organized. Projects sponsored by industry are great. \\
\hline Dr. Stwalley does a good job of making the presentations interesting. \\
\hline Definitely has the best interests of students in mind. \\
\hline
\end{tabular}




\section{Course Design}

The titles and protocols for the two courses vary slightly by academic major. ASM students typically take 'Project Planning and Management' in the fall and 'Capstone Project' in the spring. Engineering students typically take 'Project Planning and Management' in the fall and 'Agricultural Engineering Design' in the spring. Biological Engineering students, which include Food Process Engineering students, meet separately from the balance of the seniors, but they participate in the same unified department-wide presentation and final evaluation process. ASM, Environmental and Natural Resource Engineering, and traditional Agricultural Engineering students meet and conduct their class together, and this paper predominately concentrates on the experiences of those students. The fall course may be considered a lecture / seminar class, and the spring course is a project laboratory experience. Engineering students that have December graduations utilize a single combined course, 'Agricultural Engineering Project Management and Design', that meets in the fall and matches the work load of the two course sequence. ASM students do not typically get out-of-sequence, but those that do are allowed a 'Special Topics' class registration, which the ABE academic affairs committee reviews and approves for substitution in the student's academic record on an individual basis.

The fall seminar class is a one credit hour course with the following global learning objectives:

- Identify strategic project objectives and key tasks associated with specific objective completion;

- Plan the timeline and details of a medium-sized project;

- Plan the budget and financial details of an intermediate-term project;

- Provide informal progress updates to mentors and instructors regarding project progress;

- Interface and seek project sponsor's guidance;

- Understand the concepts of professionalism, ethical responsibility, and integrity when applied to technical projects;

- Enhance written communication skills through the production of a comprehensive project proposal;

- Enhance oral communication skills through the production of a proposal summary presentation;

- Learn how to respond to questions and criticism; and

- Understand the concepts of deadline, closure, and delivery.

The three credit hour spring laboratory class retains the above items and adds the following learning objectives:

- Design an environmental and natural resources system or a machine system to solve a specific need;

- Model, prototype, and test project designs within a team environment; 
- Learn how to accomplish specific tactical goals for a project within a larger operational environment (i.e. University Machine Shop \& Business Office; Corporate Sponsor's Organization); and

- Understand the compromises and load sharing necessary for effective team harmony.

The combined fall course and the improvised special topic course utilize the same global learning objectives as the spring class. Although registration for the engineering students and the ASM students is different, the classes are conducted in a combined manner, with no differentiation between the students. Expectations are the same for everyone enrolled. The course objectives are designed to align with the ABET Criterion 3(A-K) standards [10]. Although the faculty feel the objectives for the capstone sequence map well into all eleven of the criteria, Outcomes A, C, D, G, and I are thoroughly articulated. The overall experience is particularly well described by Outcome C: an ability to design a system, component, or process to meet the desired needs within realistic constraints such as economic, environmental, social, political, ethical, health and safety, manufacturability, and sustainability. It would be impossible for a student to perform any satisfactory work within the course without making some meaningful progress on this educational objective. The projects are defined through an iterative process between the faculty and the sponsors to ensure that they are both challenging and accomplishable. Objectives and constraints are identified and articulated to the students from the onset of the experience. Criterion $3 \mathrm{C}$ thoroughly describes the Purdue ABE capstone experience in an accurate and succinct manner.

Students are also directly pushed into learning objectives defined by Outcome A: an ability to apply a knowledge of mathematics, science, and engineering; and Outcome I: a recognition of the need for, and an ability to engage in life-long learning. The technical nature of the projects makes the utilization of math, science, and engineering principles absolutely vital to progress on the problems, and no student could possibly complete their project without applying the STEM topics presented in their prior undergraduate courses, fulfilling the learning objective articulated in Outcome A. Likewise, no capstone senior could ever know everything necessary to make an adequate contribution to their project with only their initial, limited, beginning knowledge base. All students are very quickly confronted with the reality of the need for independent research into the details of the specific assigned work before them. The need for a thorough review of the topics critical to individual projects is stressed during the team meetings with the course instructors, and this process addresses Outcome I. There is a strong emphasis given to the students that the communication of technical information will be critical to their success as professionals. Outcome G: an ability to communicate effectively is thoroughly addressed through a variety of means. Students are required to create oral presentations, supporting slide shows, summarization posters, and written reports. An iterative feedback process is utilized by the instructors to critique and improve the products, fulfilling Outcome G.

Finally, Outcome D: the ability to function on multidisciplinary teams is addressed through the composition of the teams and the evaluation of the individual member's 
contributions to the team by both instructors and peers. Instructors determine team make-up through an initial evaluation of a potential team member's strengths, skill sets, and departmental need. Instructors determine dysfunctionality through peer evaluations and observation. Interventions are designed to get all team members to become more tolerant, see how an immediate difficulty can be overcome, and learn to work effectively to avoid future difficulties. Students are taught to effectively divide the project work load and hold one another accountable for their performance. This process addresses Outcome D. It is the opinion of the Purdue ABE faculty that the ABET educational goals are equally as valid for ASM, our engineering technology analog major, as they are for engineering students. The overall goal of the department is to create students that can contribute to society by managing and executing sound technical projects. The capstone experience is designed to provide students with a safe environment to practice executing a project that resembles the skill requirements and decision making responsibilities that would be expected of a trained engineering or technology graduate in an entry-level job.

\section{$3 \quad$ Project Solicitation}

The capstone process at Purdue ABE serves multiple purposes for the department and faculty. Foremost is obviously the career preparation of students. This is unquestionably the first goal of the course sequence. However, there are other departmental objectives that have become beneficially entwined into the capstone process. Purdue ABE considers that relationships with the department's corporate partners are an important portion of our collective success. Accordingly, industrial projects are solicited from alumni and long-term corporate contacts for consideration by the students. This process keeps relationships with industry on-going and relevant to the issues that they are contending with. This facilitates employment opportunities for the students and research opportunities for the faculty, and it keeps the industrial partners engaged with activities in the department. These project sponsors, along with their colleagues, serve as external reviewers for the capstone projects at various times throughout the year. This brings these individuals to campus, allowing them to have personal contact with both the students and faculty, facilitating both interviewing opportunities for students and promoting continuing research projects for faculty. The positive feelings and goodwill generated by this activity are also of significant intrinsic value to the department.

Purdue University [11] has determined that an overarching strategic goal of students' career performance shall be the positive impact that they have upon the lives of others. In keeping with this philosophy, the department also looks for non-industrial development projects that match the older 'extension' goals of the land grant college mission. These projects generally come from individuals, charity, non-profit, nongovernment organizations (NGOs), or governmental organizations. As with the industrial projects, alumni and other long term contacts are approached for project abstracts. These individuals and their co-workers are also invited to participate in the external reviews of the student work. A portion of the Purdue ABE graduating seniors 
find initial employment through capstone initiated contact with these governmental bodies or NGO agencies. Additionally, faculty members within the department and the Purdue College of Agriculture are utilized for projects that have local utility to the institution. Other departments within the College of Engineering typically have their own capstone processes which adequately cover the similar needs of their faculty. Many of the faculty derived projects are legacy projects, research start-ups, or team entries for national continuing contests. Participating faculty and staff are encouraged to join in the review process and participate in the on-going evaluation of the students' work. Many internal undergraduate students wishing to further their education in graduate school find faculty matches through their capstone projects. Finally, talented and ambitious students have recently been allowed to propose their own projects for consideration. These projects are very closely reviewed and must meet the same relevance criteria as solicited projects. Although no data has been collected to support this position, it appears that students who self-select projects seem to have strong entrepreneurial instincts. It is unfortunate that these single student projects miss-out on the teamwork aspects of the general capstone experience, but the increased workload and overall responsibility associated with these projects is felt to more than make-up for this specific deficiency. However, due to the relative novelty of this approach for Purdue ABE, no self-proposed team projects have thus far been approved by the faculty.

Projects for the coming academic year are actively solicited during the summer months, prior to the start of the fall semester. The instructors' goal for this phase of the process is to have a sufficient selection of projects that are of intellectual interest to the students, so that ultimately there are roughly twice the number of potential projects than those that can actually be filled. Project abstracts are provided to the students at the first class meeting in the fall, and they are asked to review and select their top five ranked preferences from the provided list. The instructors select project teams based upon those preferences, the potential project impact, the likelihood of success, and the integration of the project within the larger goals of the department and institution. Over $90 \%$ of the students typically receive an assignment to one of their top three choices.

\section{$4 \quad$ Team Selection Philosophy}

In order to more nearly mimic the working world process, the instructors select the projects and the team assignments. The traditional work environment is modeled as closely as possible. Students are assigned to a project based upon skill sets and need. Student partnering requests are generally not accommodated, unless there is a rational, valid reason. Where possible, the instructors create mixed teams with both engineering and ASM students. It has been a long term qualitative observation of the faculty that the mixed teams are stronger than either all-engineering or all-ASM teams. Rationally, this would seem to make sense, as each variety of student brings unique and complementary skill sets to the team. Figure 3 presents the course final score averages of various teams classified as: All Engineering, Mixed, and All ASM. The 


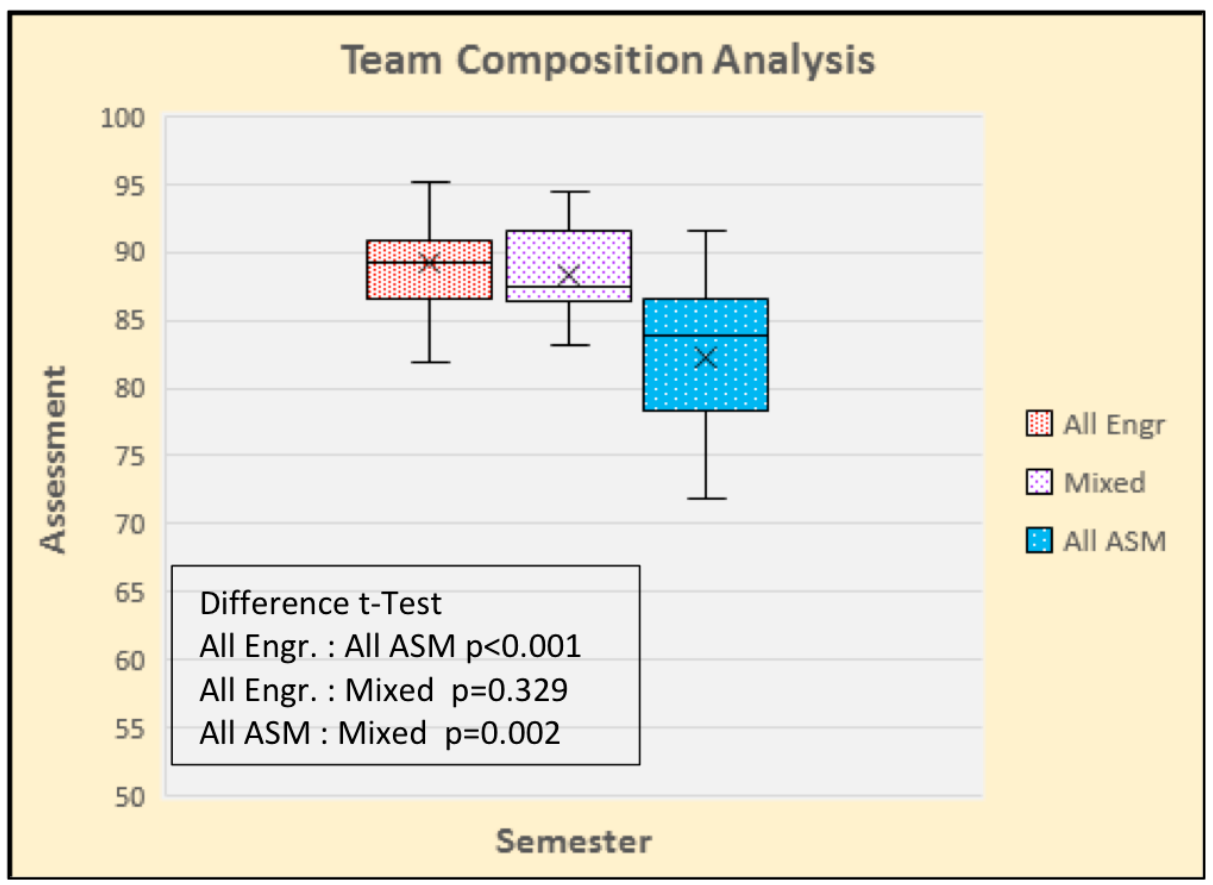

Fig. 3. Comparison of Lab Course Final Indices by Team Composition.

box and whisker graph shows the minimum and maximum values in the 'whiskers', the upper and lower quartiles with the top and bottom boxes, the median denoted by the mid-line, and the average identified by the ' $x$ '. T-tests using a confidence interval of $95 \%$ were used for all statistical testing. In comparing a limited two-year data set, the average scores were significantly different between both All Engineering (mean = 89.2, std. dev. $=3.84)$ and Mixed $($ mean $=88.4$, std. dev. $=3.58)$ groups when compared against the All ASM (mean $=82.2$, std. dev. $=6.71$ ) group, with $\mathrm{t}_{\text {engr }}(32)=3.83$, $\mathrm{p}<0.001$ and $\mathrm{t}_{\text {mixed }}(24)=3.23, \mathrm{p}=0.002$. There was no statistical difference between the All Engineering and Mixed groups, $t(16)=0.451, p=0.329$. Although this was not the completely expected result, it does show the strength of the Mixed teams in comparison to All ASM teams. The course instructors plan to continue creating Mixed teams and collecting data.

Purdue ABE believes that the project teams are larger than just the students. Communication and personal interaction are highly important aspects of the capstone experience from the faculty's perspective. Accordingly, all project sponsors must assign a key contact for the student team members. The undergraduates are required to maintain appropriate contact levels with their sponsor, which is defined as an in-depth discussion roughly every other week. There are three faculty members which serve as instructors for the Purdue ABE capstone experience. All teams are assigned a specific instructor for on-going contact. In general, one faculty member oversees the Biological Engineering projects, one supervises the Environmental and Natural Resources projects, and a third manages the Machine Systems projects. Finally, all teams are 
assigned a technical mentor. This is a faculty or staff member with specific expertise in the general area of the project. Student teams are required to continually interact with the sponsors, instructors, and technical mentors. This structure is designed to resemble the active work environment, where numerous parties have input to various projects and require status updates of specific project progress.

\section{Academic Topic Coverage}

The fall course is designed to provide students with an introduction to academic topics specifically related to the management of technical projects. There are 14 available class periods. Two of those sessions are used for oral presentations. The students are excused from the scheduled meeting of Thanksgiving week. The remaining 11 class periods are utilized for instruction. The opening period is an introduction to the course. Administrative details are covered, and the abstracts of potential projects are presented. Students are asked to respond with their selections by the end of the first week. Any student not providing a preference is warned that the consequence is assignment at the instructors' preference. Project assignments are given during the second course meeting. The expectation for project notebooks is discussed, and three team meetings with the instructors for the fall term are scheduled. These meetings cover a clarification of the project mission and a debriefing for each of the two fall term oral presentations and the written document progress submissions. The weekly team meetings with the instructors for the spring term are scheduled during the first class meeting in January.

The third class meeting in the fall covers an overview of project management. A comparison and contrast between project management and the management of continuing operations is used to illustrate key points. Research and the concepts of mission and closure are discussed. The fourth lecture deals with the design process. Two models of the overall creative design process are reviewed [12]. A sequential waterfall model describing the global tasks surrounding the creative process is presented first. This model is fairly simple, breaking the process into ideation, evaluation, and refinement phases. An iterative model then presents a block flow diagram that more nearly matches the reality of the creative design process. Students are encouraged to use the concepts of review and iteration through a creative process that includes rapid prototyping and testing. The fifth class meeting covers working within the Purdue environment. The ABE process forces the students to work inside the Purdue system to introduce functioning within a larger organization. Safety, business offices, IT specialists, and communication experts are introduced.

The fundamentals of technical writing are discussed during the sixth lecture, and the different types of oral presentations are examined during the seventh. Written submissions to the course instructors throughout the class are designed to be progressive in nature, aimed toward a comprehensive final report. Team documents are reviewed and given editorial comments midway through the fall term, at the end of the fall term, and midway through the spring term. Document improvement is a key element of this portion of a team's evaluation. Formal oral presentations are scheduled 
similarly, and corresponding slide sets are likewise reviewed by the instructors. The students make feasibility pitches during the eighth class meeting. This presentation is designed to mimic a semi-formal group meeting within an organization that is designed to select which opportunities are worth pursuing under a limited resource environment. The twelfth course meeting is used for the presentation of specific team management plans for the spring term. The management plan presentations are given to both internal and external reviewers, and they are used to present the groups' plans for the next, applied laboratory phase of the capstone experience. A technical design review occurs midway through the spring term, and the final oral presentation of the year is a poster session before sponsors, external reviewers, graduate students, and faculty.

The ninth class meeting of the fall course explores project planning, Microsoft Project ${ }^{\circledR}$, resource allocation, and budgeting. The various categories of project resources are discussed, along with how to estimate the specific needs for a specific project. Knowledge of this specific subject matter has been identified as a weakness within the Machine Systems and Environmental \& Natural Resources section of the course and a strength of the Biological section. Work is on-going to improve the low performing section using the experiences and processes of the higher performing section. Team dynamics and personality types are covered in the tenth session. This material is a relatively recent addition to the course material to address the continuing problem of dysfunctional teams. Analytical Psychology [13] and the Myers-Briggs personality tests [14] are introduced to aid students in better understanding fellow team members, the cultivation of tolerance, and how to get along with colleagues in a workplace. The actual number of dysfunctional teams is generally small, so it would be fairly tough to report improvement from this modification. However, the students do seem to find the material interesting, and there were no dysfunctional teams identified by the faculty during the year following the introduction of this material (unpublished Purdue ABE Capstone Instructor's Course Review Notes, compiled and reviewed by Robert Stwalley - Purdue ABE Capstone Sequence Instructor, 2012-17).

The eleventh lecture covers techniques for quantitative and qualitative decision making. The comparison concepts of performance metrics, the Franklin Ledger, and weighted decision making matrix calculations are introduced. External reviewers had previously identified the creation of alternative solutions and the selection between them as a serious deficiency within the Purdue ABE capstone projects (unpublished Purdue ABE Department Head / Capstone Judge Interviews, compiled and reviewed by Bernie Engel - Purdue ABE Head, 2013-16). Significant emphasis has been placed on this process by devoting most of a class period to the review of these concepts. Additionally, material by Hickerson [15] on positive career progression and the characteristic traits of a successful professional are discussed. Figure 4, from the seminar course slides, identifies the professional characteristics highlighted as critical to career success. The final class meeting of the fall is used for covering administrative details and preparation for the spring term. The spring course contains an organizational meeting during the first week of classes, and then it pulls the students together only prior to the mid-semester technical design review and the final poster presentation session. Students are to arrange their own laboratory hours in conjunction with their 


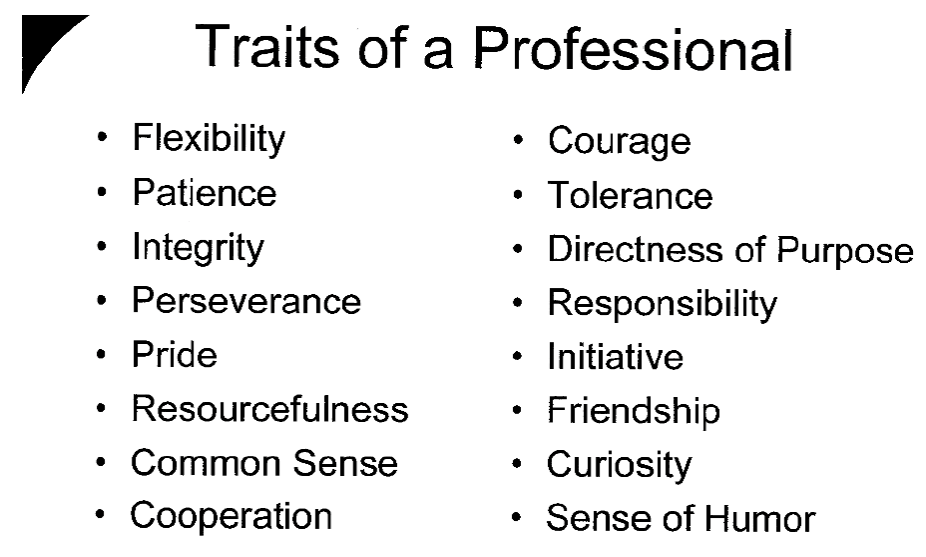

Fig. 4. Highlighted Professional Traits from Capstone Seminar Course.

team members, and they are to arrange for a weekly team meeting with a course instructor to present a progress update. The progress update format appears to be quite useful in keeping the teams moving and focused upon their project objectives. Additionally, regular meetings with the project's Technical Mentor and Sponsor are required to be scheduled.

\section{Course Deliverables}

The Purdue ABE capstone experience provides the opportunity for project teams to make four separate and distinct technical presentations and to create a single, progressively more detailed project document that culminates in a final formal report on the experience. Slides for all formal presentations require instructor approval ahead of the specific talk, and teams are required to make revisions, if their materials are found to be lacking quality. The feasibility pitch presentations have been recently introduced into the sequence midway through the fall course to provide the teams with an opportunity to run through a presentation together, prior to facing external reviewers. The management plan review is conducted at the end of the fall and is the first presentation before external reviewers. These reviewers have traditionally been tougher on the teams than internal reviewers, so the practice presentation has been added to the process to increase the experience and confidence level of the presenters. Figure 5 compares the oral presentation results for the fall management plan before the addition of the feasibility pitch with those after the addition. The addition of the preliminary talk has resulted in improved average scores for the successive oral presentation from the external reviewers and higher student satisfaction with the overall experience (unpublished Purdue ABE Capstone Course management plan \& technical design review presentation records, compiled and reviewed by Robert Stwalley - Purdue ABE Capstone Sequence Instructor, 2012-17). The management plan performance after adding the feasibility pitch $($ mean $=81.7$, std. dev. $=7.48)$ was significantly improved from the earlier performance $($ mean $=73.6$, std. dev. $=7.78), t(42)=3.98, \mathrm{p}=0.000$. 


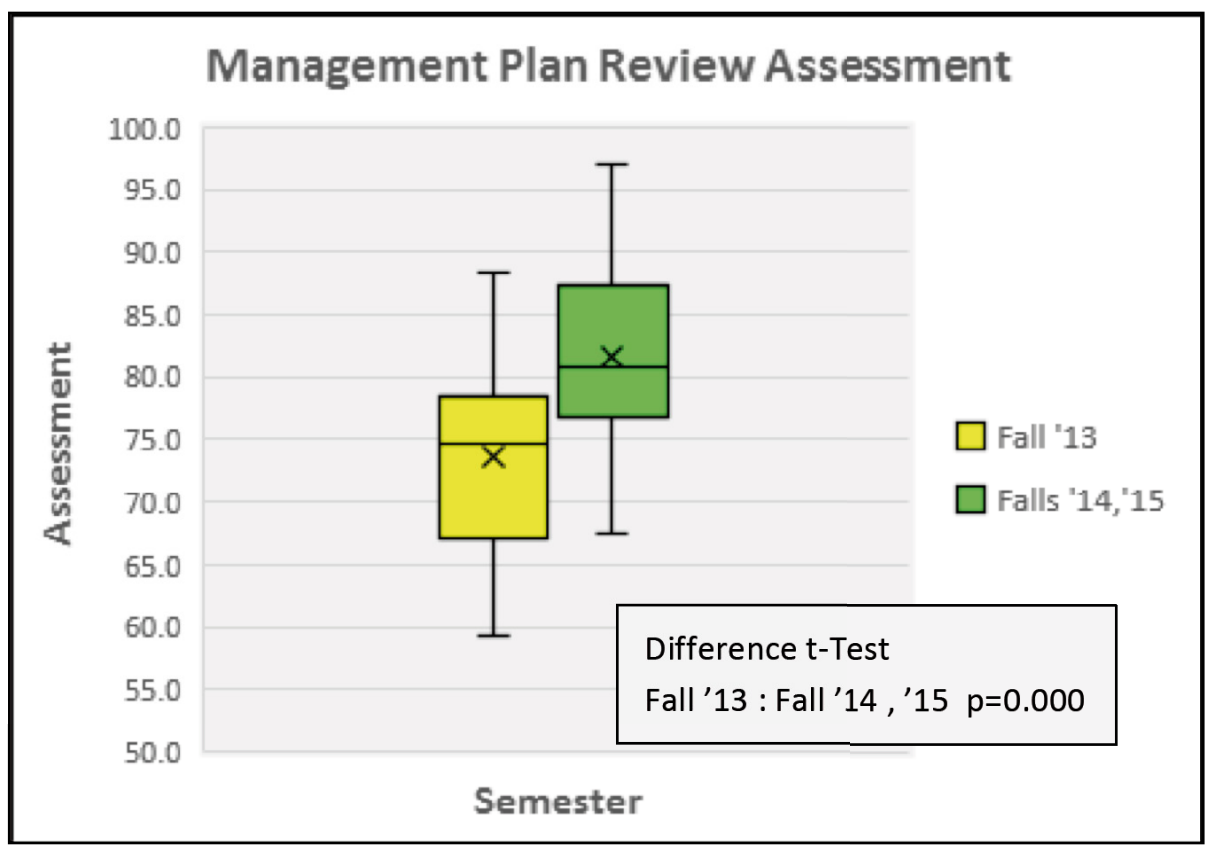

Fig. 5. Comparison of Management Plan Scores Before and After the Addition of an Earlier Feasibility Pitch.

A formal technical design review is conducted midway through the spring term. This presentation is given to the same internal and external reviewers. The student teams are expected to have made adjustments based upon earlier comments, but only at this mid-point during the laboratory phase of the sequence are the actual designs finalized enough for effective technical criticism. The scheduling of these presentations prior to spring break allows time for the teams to make adjustments to their designs and project objectives before the end of the spring class. Figure 6 shows the performance results for the spring technical design review before and after the addition of the feasibility pitch. A statistically significant post-change improvement (mean $=83.6$, std. dev. $=7.66$ ) was also seen with the technical design review when compared to the data from before the addition of the feasibility pitch (mean $=75.9$, std. dev. $=8.90), \mathrm{t}(33)=3.35, \mathrm{p}=0.001$.

The final presentation of the Purdue ABE capstone sequence for the students is an elevator pitch about the overall project. This is the larger course closure event, and it is conducted using a project poster document created to describe the overall experience. The final project poster is created by the student teams according to a recommended format, and it must be approved by both the instructor and the technical mentor for the project, prior to printing. Teams are provided with the opportunity to have their elevator pitch taped and critiqued before the final presentation function at the end of the spring course. This is a new innovation and has resulted in improved overall scores and student satisfaction (unpublished Purdue ABE Capstone Course poster session presentation records, compiled and reviewed by Robert Stwalley - Purdue 


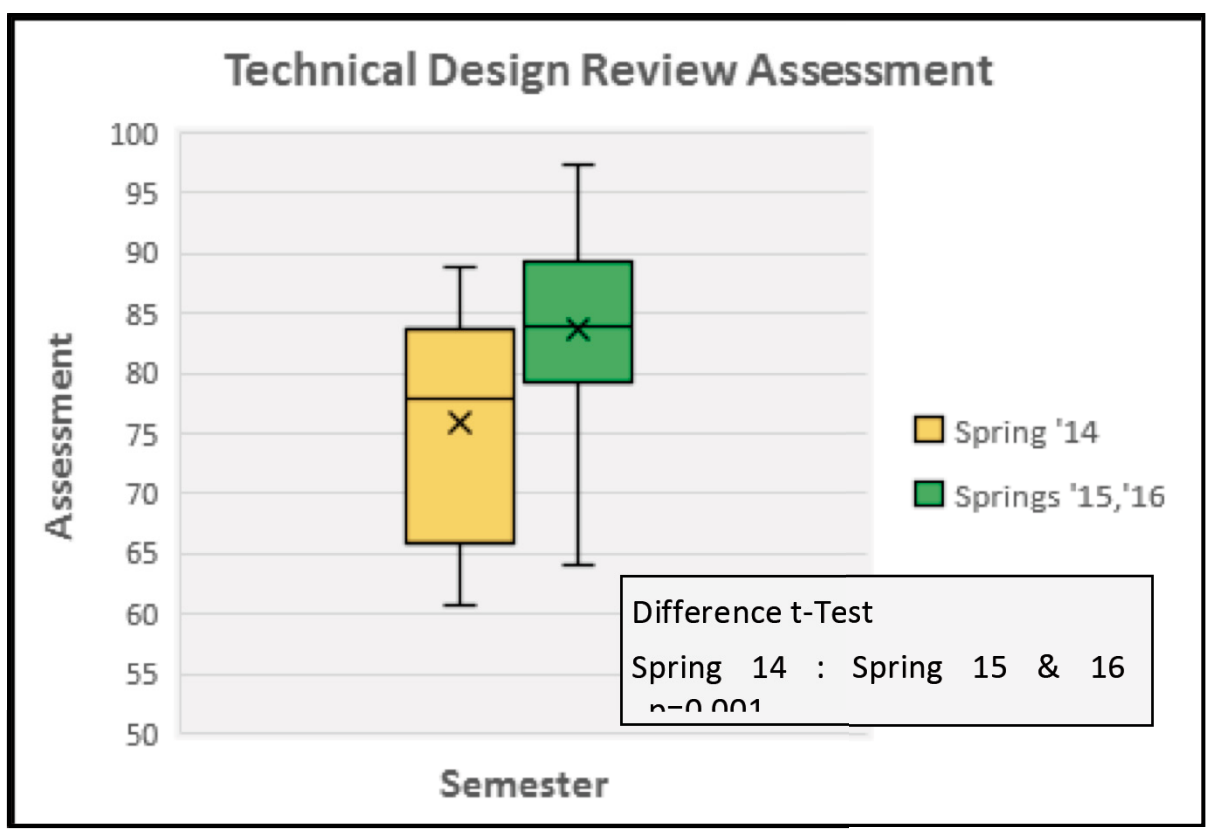

Fig. 6. Comparison of Technical Design Review Scores Before and After the Addition of an Earlier Feasibility Pitch.

ABE Capstone Sequence Instructor, 2012-17). Figure 7 presents poster session scores from before and after the introduction of the elevator pitch videotaping sessions. Scores are clearly higher after the videotaping was instituted. The addition the videotaping was strongly correlated to a higher score $($ mean $=81.8$, std. dev. $=7.07)$ compared to the results prior to the practice session (mean $=67.7$, std. dev. $=6.59), \mathrm{t}(48)$ $=8.02, \mathrm{p}<0.001$. The poster and elevator pitch are judged by both internal and external reviewers to determine first and second place winners within similar subgroupings of roughly seven teams. The overall experience is celebrated at a year's end banquet for the students and their guests. Like the evaluations of the more formal presentations, students appear to benefit from the practice run at the specific communication form.

Each team is required to produce a single formal written document regarding their capstone project. The teams work on and refine the document throughout the year. This document is presented to the project sponsor at the conclusion of the sequence. A draft of each team's term paper is due roughly at the same time as the oral presentations. An instructor reviews the documents and provides feedback to the teams as the course progresses. The expectations for progress on the document are clearly outlined by the instructors ahead of time, and faculty approved rubrics are used and provided to the students for use in document improvement (unpublished Purdue Capstone Course assessment documents, created and reviewed by Carol Weaver - Purdue ABE Alumni Relations \& Communication Specialist, 2016). Improvement is tracked and used for ABET purposes. 


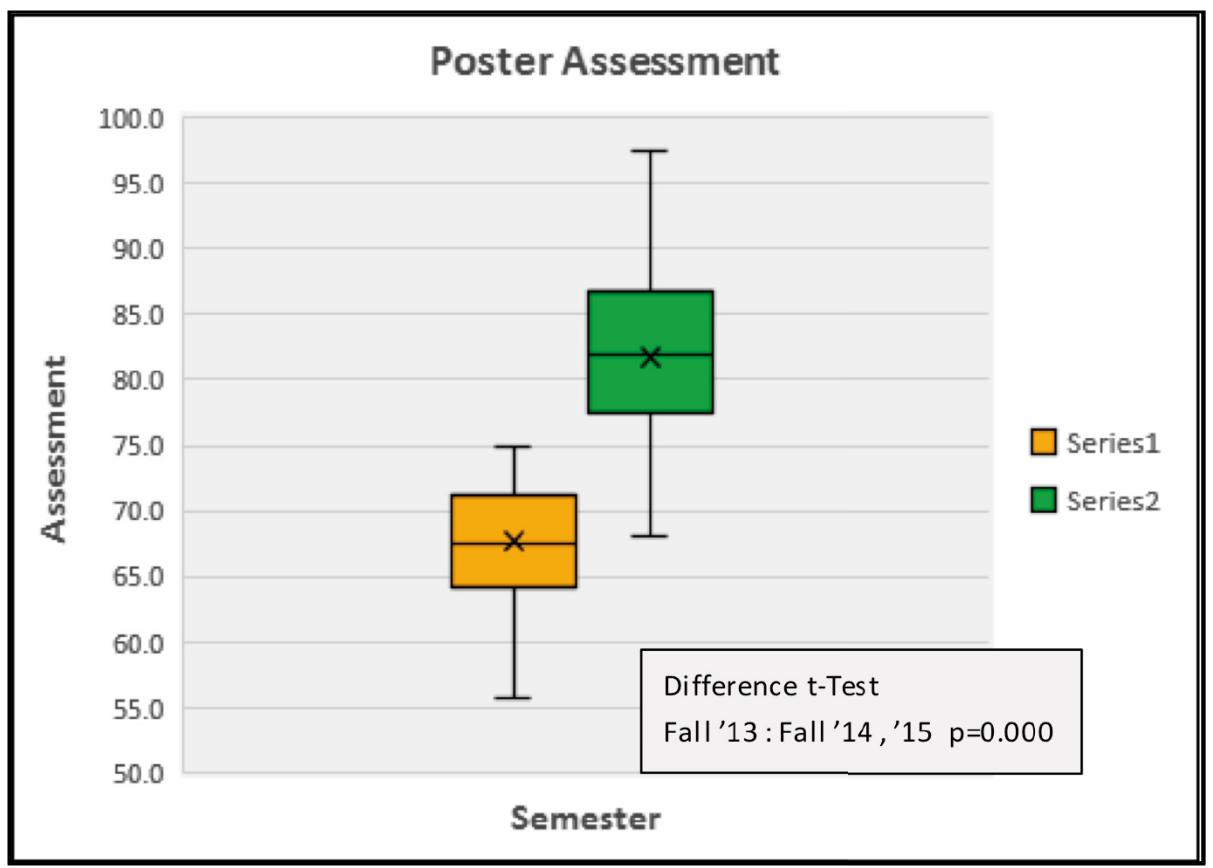

Fig. 7. Comparison of Technical Design Review Scores Before and After the Addition of an Earlier Feasibility Pitch.

\section{Continuing Improvement and Closure}

Purdue ABE has a well-founded culture of continuous improvement in academic offerings within the faculty. Students are polled regarding their opinions of classes, and faculty review data regarding certain educational outcomes annually (unpublished Purdue ABE Faculty Retreat notes, compiled and reviewed by Bernie Engel - Purdue ABE Head, 2016). Improvements are discussed and instituted based upon consensus of the faculty directly involved. Those changes are then examined for effectiveness. There have been several modest changes to the Purdue ABE capstone sequence over the last few years to improve the learning outcomes of the students. Stwalley [16] has previously discussed some of these course protocols and changes.

In response to external reviewers, specific oral presentation objectives have been clarified, and slide show visual aids now undergo preliminary review. An additional 'practice' presentation has been added to the schedule, and elevator speeches are videotaped and provided to the students for self-review, prior to the final presentation session. The types of oral presentations typically seen in a business environment are now covered in the academic portion of the sequence. Two additional rounds of progress submission review and faculty critique for the written documents have been added to improve the quality of those materials. Academic material covering personalities and motivational strategies has been added to the academic section of the cap- 
stone sequence to aid students in understanding how to combat team dysfunctionalities. Weekly progress meetings are now held on a regular basis, and teams that miss meetings are penalized and required to reschedule them. A series of 'Skill Sharpener' sessions, reviewing useful professional skills and technical training that may have grown rusty through disuse, has been added to the capstone curriculum in response to both student requests and external reviewers' comments. Review of these modifications is on-going, but anecdotally, it has been noted that long-term acquainted external reviewers have commented positively on the recent improvements. The students seem happy with the overall experience and comment positively about the capstone sequence in their exit interviews upon graduation. In conclusion, it seems fair to state that the iterative design process taught to Purdue ABE students is practiced by the faculty in their management and administration of the capstone course sequence. Outcomes are evaluated, and the overall process is incrementally adjusted to improve the results.

\section{$8 \quad$ References}

[1] US News \& World Report, 'Agricultural \& Biological Engineering program rankings', http://colleges.usnews.rankingsandreviews.com/best-colleges/rankings/engineering, Accessed 10 December 2015.

[2] Purdue University Center for Career Opportunities, 'ABE \& ASM historical placement data', https://www.cco.purdue.edu/students/where Purdue University students go.aspx\#fi rst-destination-data, Accessed 4 November 2016.

[3] Howe, S., \& Wilbarger, J., 2005 National Survey Of Engineering Capstone Design Courses Paper presented at 2006 Annual Conference \& Exposition, Chicago, Illinois. https://peer.asee.org/1023, June 2006.

[4] Howe, S., \& Lasser, R., \& Su, K., \& Pedicini, S., Content In Capstone Design Courses: Pilot Survey Results From Faculty, Students, And Industry Paper presented at 2009 Annual Conference \& Exposition, Austin, Texas. https://peer.asee.org/5239, June 2009.

[5] Co, C., \& Turner, B., \& Cheville, A., A Pre Capstone Course Designed To Improve Student Performance On Open Ended Design Projects Paper presented at 2007 Annual Conference \& Exposition, Honolulu, Hawaii. https://peer.asee.org/1612, June 2007.

[6] Mohammed, J., \& Dimmitt, N. J., A Coursework Plan for Improving Skills Necessary for Successful Capstone Projects Paper presented at 2012 ASEE Annual Conference \& Exposition, San Antonio, Texas, June 2012. https://peer.asee.org/20796

[7] McVey, F. D., \& Lang, J. D., Industry Expectations Of New Engineers ... A Survey To Assist Curriculum Designers Paper presented at 1998 Annual Conference, Seattle, Washington. https://peer.asee.org/7187, June 2008.

[8] Kimble-Thom, M.A. \& Thom, J.M., Academic and Industrial Perspectives on Capstone Course Content and The Accompanying Metrics, Paper presented at the 2005 ASEE/IEEE Frontiers in Education Conference, Indianapolis, Indiana, October 2005. https://doi.org/10.1109/FIE.2005.1612137

[9] Brumm, T.J., Mickelson, S.K., Steward, B.L., \& Kaleita, A.L., Competency-based Outcomes Assessment for Agricultural Engineering Programs, International Journal of Engineering Education 22-6, pp1163-1172, 2006.

[10] ABET, 'Criteria for Accrediting Engineering Programs', 2014. 
Paper-Assessing Improvement and Professional Career Skills in Senior Capstone Design through...

[11] Gallop Organization, 'Great Jobs, Great Lives - Gallop-Purdue Index 2015 Report', http://www.gallop.com/services/185888/gallup-purdue-index-report-2015.aspx, Accessed 10 December 2015.

[12] Purdue University EPICS Program, 'EPICS Design Model', 2012.

[13] Clemens, S. M. \& Jung, C. G., The Collected Works of C. G. Jung, Princeton University Press, 1978.

[14] Gardner, W. L. \& Martinko, M. J., 'Using the Myers-Briggs Type Indicator to study managers: A literature review and research agenda', Journal of Management 22, 1996, pp. 4583. https://doi.org/10.1177/014920639602200103

[15] Hickerson, K., 'Elementary Life Skills', http://circle.adventist.org/files/download/ 21 lifeskills.pdf, Accessed 15 July 2013.

[16] Stwalley III, R.M., 'Professional Career Skills in Senior Capstone Design', 2016 ASEE Capstone Conference, Columbus, Ohio, 2016.

\section{$9 \quad$ Author}

Robert M. Stwalley III, Ph.D., P.E. is an American engineer with over 30 years of industrial, consulting, and instructional experience. Dr. Stwalley is an Assistant Clinical Professor of Agricultural \& Biological Engineering at Purdue University, where he teaches core engineering and technical science courses, along with the senior capstone sequence. Dr. Stwalley strongly believes in applying the same datadriven design, test, and improve process to teaching as is used in engineering product and process development.

Article submitted 05 July 2017. Published as resubmitted by the author 23 August 2017. 